\title{
Integrating mixed-cell CA model and Bayesian belief networks to optimize ecosystem services for ecological restoration and conservation
}

\author{
Shuang Zhou ${ }^{1}$ and Li Peng ${ }^{2}$ \\ ${ }^{1}$ Institute of Mountain Hazards and Environment Chinese Academy of Sciences \\ ${ }^{2}$ Institute of Mountain Hazards and Environment, CAS
}

September 25, 2021

\begin{abstract}
The complexity and uncertainty of land use and environmental factors pose challenges to the management decisions of ecological restoration and conservation.We integrated the mixed-cell CA model and Bayesian belief networks to develop an innovative method for optimizing ecosystem services under different land development scenarios, including consideration of the uncertainty and variability of factors. The southern region of Sichuan Province, China, was selected as an example. We first established three development scenarios between 2015 and 2035, namely, natural development scenario (NDS), ecological protection scenario (EPS), and cultivated land protection scenario (CLPS). The MCCA model was utilized to simulate the land use pattern in 2035 under different scenarios. We then construced a BBN-based model to investigate the carbon sequestration, grain supply, soil conservation, habitat quality, and water yield in 2035 under uncertain scenarios.After the sensitivity analysis and evaluation of the model, we determined the state combination of influential factors at various ecosystem service levels and the ecological restoration and conservation key areas. The obtained result showed that the key influencing factors impacting the ecosystem services level included NPP, Slope, forestland and ET, and the state combination corresponding to the highest level of ecosystem services was predominantly distributed in regions with the highest NPP, the highest Slope, the highest forestland area and low ET.Based on this finding, we proposed some suggestions for ecological restoration and conservation of key areas. This model considers uncertainties and is capable of providing scientific recommendations on restoration and conservation; therefore, it can serve as an effective tool to assist stakeholders in making decisions.
\end{abstract}

\section{Hosted file}

LDD(1).docx available at https://authorea.com/users/436112/articles/538667-integratingmixed-cell-ca-model-and-bayesian-belief-networks-to-optimize-ecosystem-services-forecological-restoration-and-conservation

\section{Hosted file}

figures.rar available at https://authorea.com/users/436112/articles/538667-integratingmixed-cell-ca-model-and-bayesian-belief-networks-to-optimize-ecosystem-services-forecological-restoration-and-conservation 